\title{
NEW APPROACH TO BALL MILL MODELLING AS A PISTON FLOW PROCESS
}

\author{
Eduard Guasch*, Hernan Anticoi, Sarbast A. Hamid, Josep Oliva, Pura Alfonso, Teresa Escobet, Lluís \\ Sanmiquel, Marc Bascompta \\ Departament d'Enginyeria Minera, Industrial i TIC, Universitat Politècnica de Catalunya Barcelona Tech, Av. \\ Bases de Manresa 61-63, Manresa (08242) Barcelona, Spain \\ eduard.guasch@upc.edu,hernan.anticoi@upc.edu, sarbast.a.h@emrn.upc.edu,josep.oliva@upc.edu, \\ pura@emrn.upc.edu, teresa@epsem.upc.edu, lluis.sanmiquel@upc.edu,marc.bascompta@upc.edu
}

*Corresponding author: eduard.guasch@upc.edu

\begin{abstract}
Comminution represents one of the most important operations in mineral processing due to the high energy cost and tool wear. This paper presents a new population balance model (PBM) of ball mills that understands the ball mill process as a hybrid of a perfectly mixed mill and piston flow mill. Usually, PBM for grinding is related to a perfectly mixed mill. In this case, the piston flow was introduced for a more realistic process. The ball mill modelling process is described as the point where the feed entering the distribution size is coarse, and where there is an overflow and discharge of the mill, the distribution size is fine and equivalent to the product distribution size. In this work, the evolution of the size of particles along the mill piston flow process was studied. The relationship between the particle size and position in the length of the mill was established. The equation of the balance population model was formulated, and the parameters were determined for a tungsten ore.
\end{abstract}

\section{Keywords}

Ball Mill, Grinding, Modelling, Piston Flow, Population Balance Models 


\section{Introduction}

Large amounts of energy are necessary to reduce the particle size in ore processing, usually representing a significant amount of the total expenses of the processing (Datta and Rajamani, 2002). Selection of the optimal parameters to reduce the particle size is a key factor in these operations (Grupta and Sharma, 2014; Zhang et al., 2016). The development of models to predict the comminution behaviour of particles can determine the optimal parameters for reducing the particle dimension. Population balance modelling has been widely and successfully used in ball mills (King, 2001; Hennart et al., 2009); it was initially introduced by Epstein (1947) and used for comminution models (Austin et al., 1984; Venkataraman and Fuerstenau, 1984; Morrell et al., 1993; King and Bourgeois, 1993; King 2001; Wang et al., 2012). The Population Balance Model (PBM) is referred to as a simple mass balance for the size reduction. This model allows the particle size distribution to be controlled and the breakage mechanisms during comminution to be found (Bilgili et al., 2004, 2006). It is based on the determination of particle size distributions and divided into size classes. The fundamental postulate supports the kinetic model which states that the rate of breakage of material out of a size class is proportional to the amount of material of size $i$ in the mill; it is detailed in Equation (1):

$$
\text { Rate of breakage }=k_{i} M m_{i}
$$

where $k_{i}$ is the specific rate of breakage, $M$ is the mass of material in the mill, and $m_{i}$ is the fraction of the mill contents in size class $i$. The formulation of PBM for grinding has been developed by different authors (e.g., Austin et al., 1984). In brief, a mass balance for class $i$ in a well-mixed milling process is achieved by Equation (2) (Austin, 1972; Datta and Rajamani, 2002):

$$
\frac{d m_{i}(t)}{d t}=-k_{i} m_{i}(t)+\sum_{j=1}^{i-1} b_{i j} k_{j} m_{j}(t)
$$

where $\mathrm{m}_{\mathrm{i}}(\mathrm{t})$ is the mass fraction of particles with size class $i$ at milling time $t$. The first term after the equal sign is the disappearance or breakage rate at which particles of class $i$ are broken into smaller particles. The second term represents the summed rate at which particles in all classes $j<i$ are broken into class $i$, where $i$ and $j$ are size class indices extending from size-class 1 , containing the coarsest particles, to size-class $N$, containing the smallest particles. In this equation, $b_{i j}$ is the breakage function. Breakage simulation can be obtained with the use of discrete elements (Cleary and Morrison, 2011; Wang et al., 2012; Weerasekara, et al., 2013; Soni et al., 2015).

The equation of the PBM for a perfectly mixed mill derives directly from a simple mass balance for materials in any specific size class. This would be the simplest case, but it is also sufficiently realistic. This case assumes that once the material is inside the mill, it is broken directly to the product particle size. All of the material inside the mill has the same characteristics.

In practice, there are some restrictions when the material inside the mill moves towards the outlet stream. Larger particles do not pass through the discharge grate, and then they are not released from the mill. In the overflow discharge mills, when the discharge grate is not used, larger particles do not leave the mill because finding a path to rise in the medium bed to the discharge is difficult (King and Schneider, 2011). On the other hand, very small particles move readily with water and are easily discharged. Therefore, the discharge end of the mill behaves as a classifier, which permits the selective discharge of the smallest particles and recycles the larger particles back into the body of the mill. Some authors state that transport is separated from breakage events. To enable a dynamic simulation capability for non-steady-state simulation and control modelling, a new model structure based on dynamic time stepping was proposed by Yu et al. (2014).

The present work aims to study the evolution of particle size along the mill process to establish the relationships between particle size and its position along the mill. The study is based on the population balance models to determine the evolution of the particle size during the grinding process. It can be assumed that the distribution size is coarse at the feed inlet, the distribution size is fine at the overflow and discharge of the mill, 
and it is the product distribution size. Given this, it is credible that the distribution size changes along the mill; therefore, the real process can also be partly interpreted as a piston flow mill.

\section{Materials and methods}

\subsection{Materials}

Approximately $400 \mathrm{~kg}$ of a low-grade tungsten ore from the Mittersill Mine, Austria, were used for the experiments. These are calc-silicate metamorphic rocks mainly comprising hornblende, biotite, plagioclase and epidote, with scheelite as the W-bearing mineral. The sample was crushed by a KHD Humblot Wedag jaw crusher, sieved and classified by size classes of $-5+4 \mathrm{~mm},-4+3.15 \mathrm{~mm},-3.15+2 \mathrm{~mm}$ and $-2+1 \mathrm{~mm}$ to perform the experiments. For the experiments, these size classes were mixed to have a feed particle size distribution.

\subsection{Experimental}

The methodology can be divided into three different stages: (1) Preparation of the materials and determination of operative parameters, (2) selection of the model and executing experiments, and (3) modelling and back-calculation to find the different parameters of the breakage and selection functions.

Four experiments were performed with a laboratory scale overflow ball mill. Three were conducted to study the process and determine the parameters, and the last was for validation. The internal dimensions of the mill are $48.26 \mathrm{~cm}$ in length and $22.86 \mathrm{~cm}$ in diameter. The tests were performed at $70 \%$ of the critical speed and charged with 300 balls of $26.8 \mathrm{~mm}$ in diameter with a residence time between 76 and 85 minutes. A window in the wall of the mill was built to control the activity inside the mill at a specific time. The tests started with the mill empty of material with only balls charging. The flow was constant during all of the experiments; initially, the mill ran in a non-stationary stage, and the experiment continued until it reached the stationary stage (same flow in the inlet and outlet). At this time, the particle size distribution of the product and three points along the mill were determined for each assay to prove the piston flow process. The mill was stopped to collect the samples, the cover was removed, and three different samples from three places along the mill were taken (Figure 1). The first sample was taken from the first $5 \mathrm{~cm}$ of the mill, the second from the centre, and the last from the last $5 \mathrm{~cm}$ of the mill. Each sample was a representative mass, approximately $500 \mathrm{~g}$, from an entire cross-section of the three places described. The charge fraction inside the mill was also determined (Table 1). MATLAB software and the backcalculation globalsearch solver were used to adjust the parameters.

Table 1. Operative parameters of the different experiments. $\mathrm{L}$ is the internal mill length; $\mathrm{D}$ is the internal mill diameter; $J_{R}$ is the fraction of the mill volume occupied by the bulk rock charge; and $J_{B}$ is the fraction of the mill volume occupied by the bulk ball charge.

\begin{tabular}{lrr} 
Parameters & & Unit \\
\hline $\mathrm{L}$ & 0.48 & $\mathrm{~m}$ \\
$\mathrm{D}$ & 0.23 & $\mathrm{~m}$ \\
$\mathrm{~N}^{\text {o balls }}$ & 300 & \\
$\mathrm{~J}_{\mathrm{B}}$ & $53.14 \%$ & \\
$\mathrm{~J}_{\mathrm{R}}$ & $22.21 \%$ & \\
Flow & 80 & $\mathrm{~g} / \mathrm{min}$ \\
Residence time & $76.5-85$ & $\mathrm{~min}$ \\
Power & 0.75 & $\mathrm{~kW}$
\end{tabular}




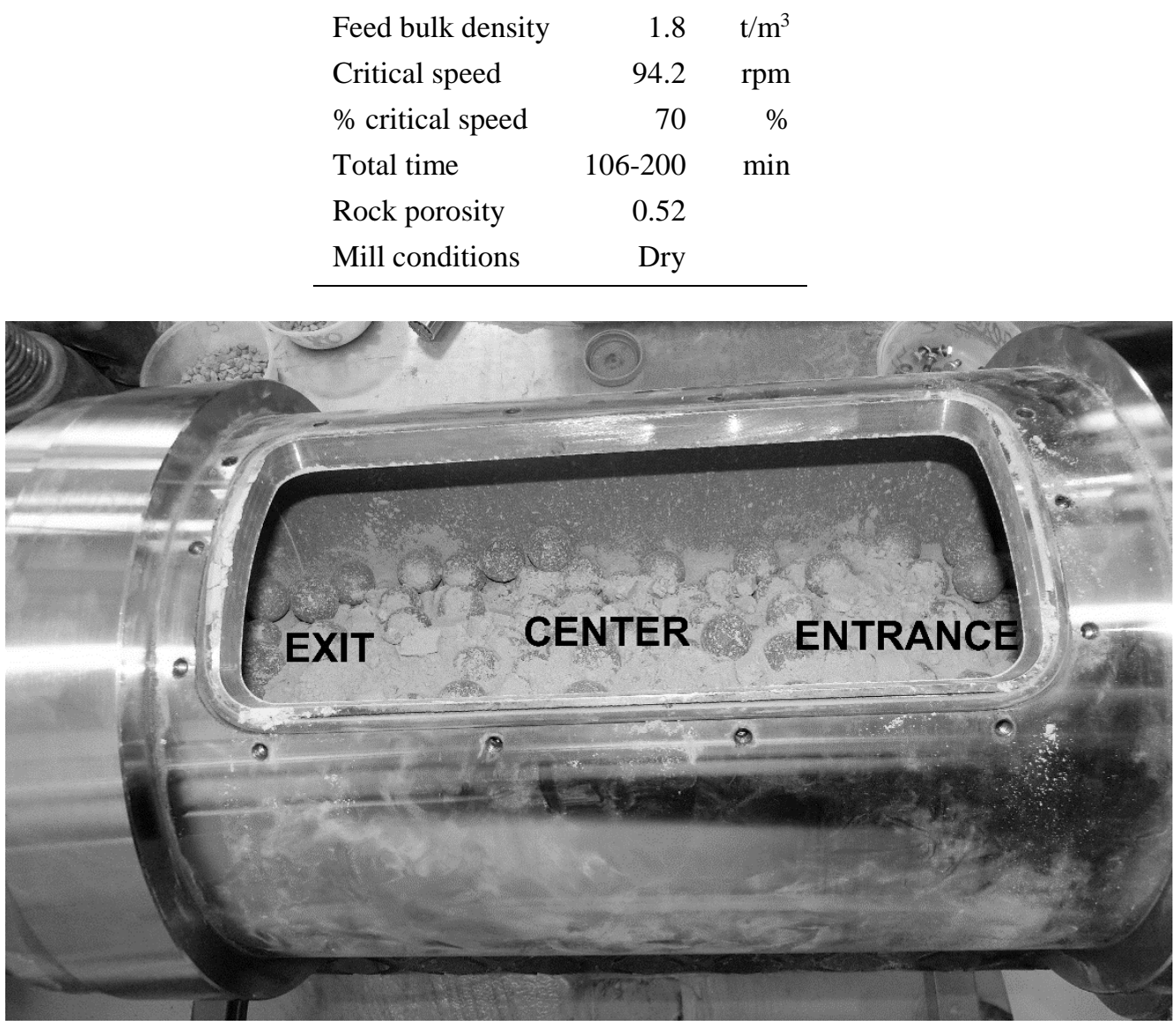

Figure 1. Interior of the mill during an experiment. Coarse particles are fine compacted aggregates dropped from the window.

\section{Modelling}

Two main hypotheses have been proposed: (1) Perfectly mixed milling occurs once the material enters into the mill. (2) A percentage of material behaves as a piston flow phenomenon when a selection function discriminates the particle sizes with a certain probability to be influenced by this mechanical breakage. Figure 2 shows the flux for this proposed model.

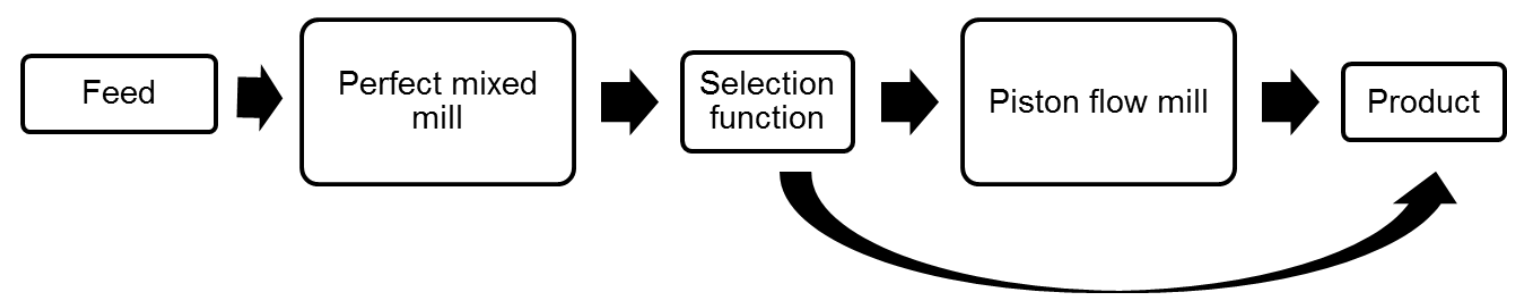

Figure 2. Diagram of the process proposed for a ball mill. 
The perfectly mixed mill dynamic Equation (2) for PBM can be solved in a stationary state as a mathematical discretization assuming that the content of the mill is perfectly mixed at a first stage (Equation 3 ), $\mathrm{m}_{\mathrm{i}}=\mathrm{p}_{\mathrm{i}}^{\mathrm{P}}$ :

$$
p_{i}^{P}=\frac{p_{i}^{F}+\sum_{j=1}^{i-1} b_{i j} k_{j} \tau p_{j}^{P}}{1+k_{i} \tau}
$$

where $\mathrm{m}_{\mathrm{i}}$ is the fraction of mill content in size class $i, \mathrm{p}_{\mathrm{i}}^{\mathrm{P}}$ is the product of the mill in a differential mass, $\mathrm{p}_{\mathrm{i}}^{\mathrm{F}}$ is the feed in a differential mass, $b_{\mathrm{ij}}$ is the breakage function, $\mathrm{k}_{\mathrm{i}}$ is the specific rate of breakage and $\tau$ is the residence time. Austin et al. (1987) proposed the variation of the specific rate of breakage with particle size as Equation (4).

$$
k\left(d_{p}\right)=\frac{s_{1} d_{p}^{\alpha}}{1+\left(d_{p} / \mu\right)^{\Lambda}}
$$

where the value of $\alpha$ is a positive number, which is characteristic of the material; although the $\alpha$ value will vary with the mill conditions, $\mu$ is the particle size that fixes the maximum position, and $\Lambda$ is a positive number that is an index of how rapidly the breakage rate declines with increasing size. The standard form presented by Whiten et al. (1979) is used in Equation (5) for the breakage function:

$$
B(x, y)=k\left(\frac{x}{y}\right)^{n 1}+(1-k)\left(\frac{x}{y}\right)^{n 2} \text { for } x \geq y_{0}
$$

where $\mathrm{k}, \mathrm{n}_{1}$ and $\mathrm{n}_{2}$ are the parameters of the model. The mathematical function that discriminates between the particles entering the piston flow and those that are not affected is shown in Equation (6).

$$
S(d p)=\left\{\begin{aligned}
S_{i} & =\omega e^{\beta d p} & & S<1 \\
S & =1 & & S \geq 1
\end{aligned}\right.
$$

where $\omega$ and $\beta$ are the parameters of the selection function. The process in the piston flow is described as the reduction of the particle size along the mill. Figure 3 shows the mass balance in any increment (dx) along the mill (Equation 7).

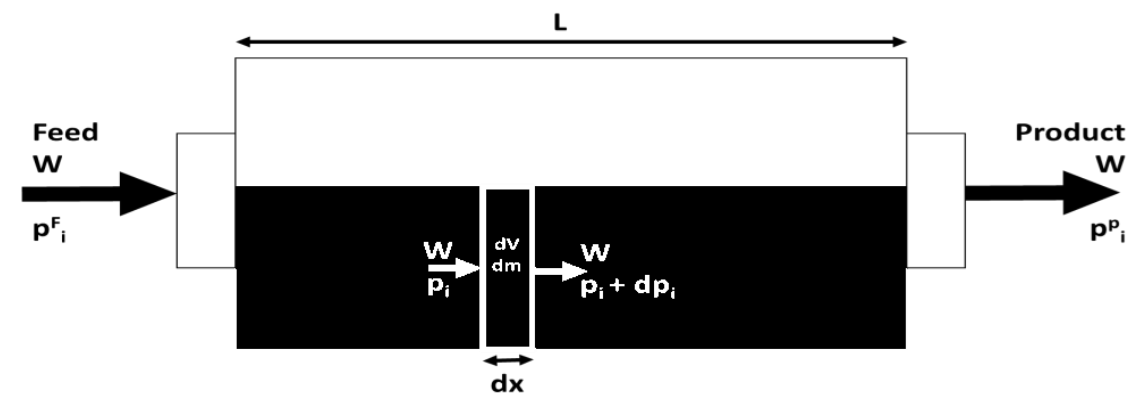

Figure 3. Scheme of the piston flow in a ball mill.

$$
W\left(p_{i}+d p_{i}\right)=W p_{i}+\left(\sum_{j=1}^{i-1} b_{i j} k_{j} p_{j}-k_{i} p_{i}\right) d m
$$

Then, $d m$ can be written as in Equation (8). 


$$
d m=\rho J \frac{\pi D^{2}}{4} d x
$$

where $\rho$ is the density of the mineral, $\mathrm{J}$ is the fraction of the mill filled by mineral, and D is the diameter of the mill. Equations (9) and (10) are obtained by introducing Equation (8) into Equation (7).

$$
\begin{gathered}
W\left(p_{i}+d p_{i}\right)=W p_{i}+\left(\sum_{j=1}^{i-1} b_{i j} k_{j} p_{j}-k_{i} p_{i}\right) \rho J \frac{\pi D^{2}}{4} d x \\
\frac{4 W}{\rho J \pi D^{2}} \frac{d p_{i}}{d x}=\sum_{j=1}^{i-1} b_{i j} k_{j} p_{j}-k_{i} p_{i}
\end{gathered}
$$

which have the following boundary conditions:

$$
\begin{aligned}
& p_{i}(x=0)=p_{i}^{F} \\
& p_{i}(x=L)=p_{i}^{P}
\end{aligned}
$$

Equations (13) and (14) are achieved by applying the batch grinding kinetic equation solved by Reid (1965) for the piston flow phenomenon.

\section{Results and discussion}

$$
\begin{gathered}
p_{i}^{P}=\sum_{j=1}^{i} A_{i j} \exp \left(-\frac{k_{j}}{\frac{4 W}{\rho J \pi D^{2}}} L\right) \\
A_{i j}=\left\{\begin{array}{cc}
0 & i<j \\
\sum_{l=j}^{i-1} \frac{b_{i l} k_{l}}{k_{i}-k_{j}} A_{l j} & i>j \\
p_{i}^{F}-\sum_{l=1}^{i-1} A_{i l} & i=j
\end{array}\right.
\end{gathered}
$$

The experiments developed show that the milling process is regulated in the first step by a perfectly mixed, continuous mill, and this explains the existence of a gap from the feed distribution particle size to the particle size distribution in the feed inlet. Then, the grinding continues and its progress is regulated by the piston flow. Figure 4 represents the plot of different particle size distributions inside the mill in the four experiments developed. This phenomenon was observed in all experiments. 

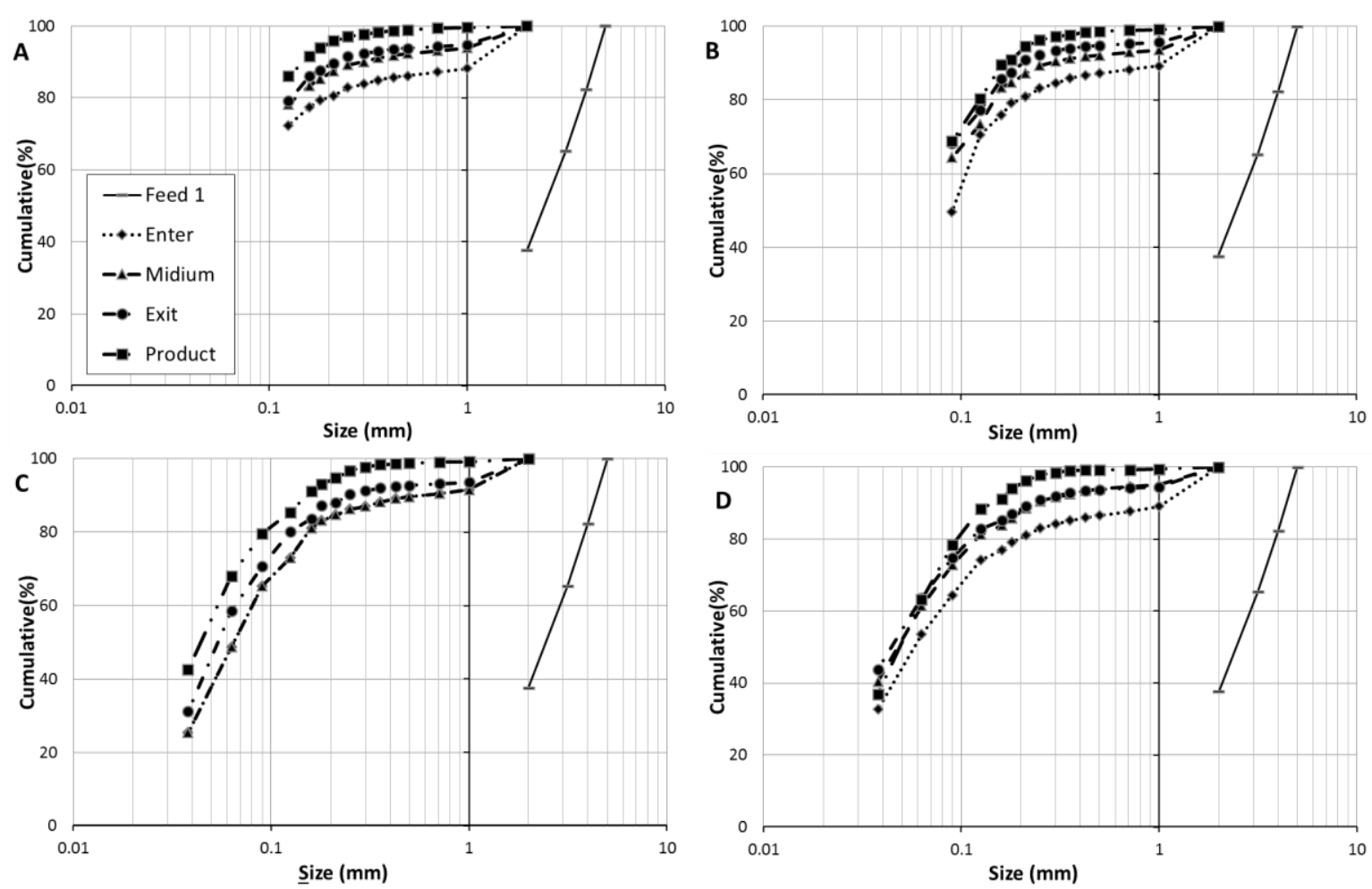

Figure 4. Different curves of particle size distributions showing the piston flow phenomenon inside the laboratory scale ball mill and the product (feed inlet, centre and exit). (A) to (D) represent the experiments 1, 2, 4 and 5, respectively.

The reduction rate obtained from the product and feed particle size distributions are 39, 32.5, 40 and 41 for experiments 1,2, 4 and 5, respectively. These high reduction values are explained by the long residence time (Table 1).

The differential mass inside the mill with respect to the differential mass of the product exhibited the same behaviour as the cumulative mass. The piston flow phenomenon is clearer in the coarsely size particles, where the differential mass curve decreases along the mill and increases again for the finest particle sizes (Figure 5). The line that defines the minimum of this differential mass draws the mass fraction, which is in a perfectly mixed continuous mill and not affected by the piston flow process. 


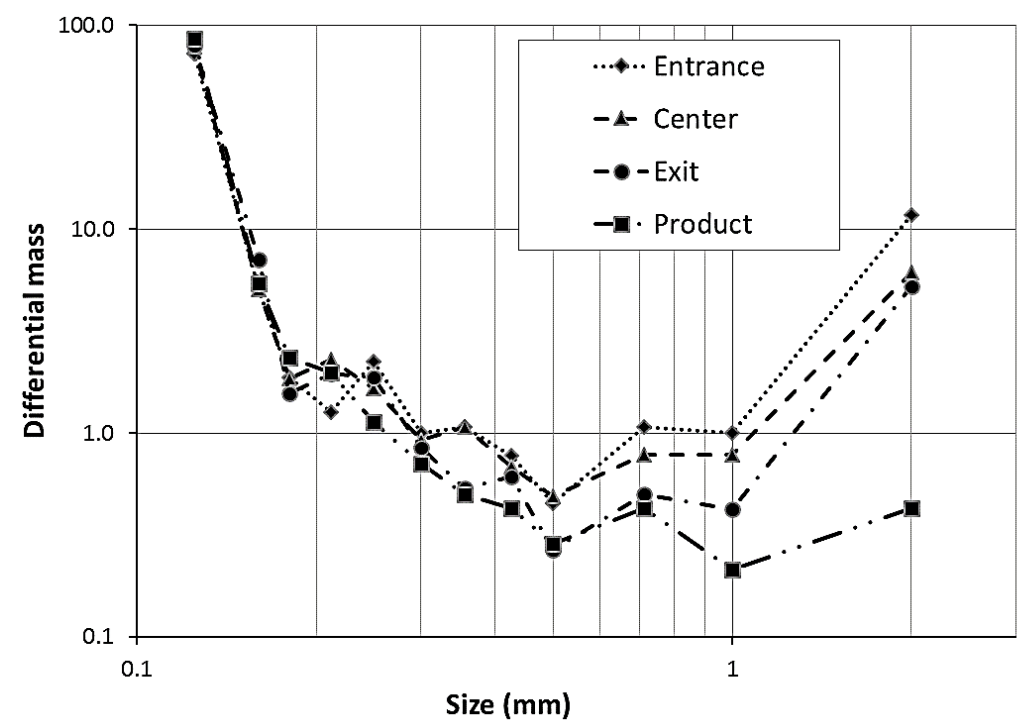

Figure 5. Plot of the differential mass of the different parts inside the mill and the product of experiment 1.

The difference between the particle size product and the particle size in the feed inlet of the mill represents the selection function, and this is defined in the coarse particle sizes, where the reduction process was observed. The selection function for this work represents the mass fraction of the flow in the piston flow mill. From this criterion, this mathematical function is used to discriminate between the particles entering the piston flow and those that are not affected. Figure 6 plots the experimental values of this difference and the exponential regression. Parameters of these functions are indicated in Table 2.

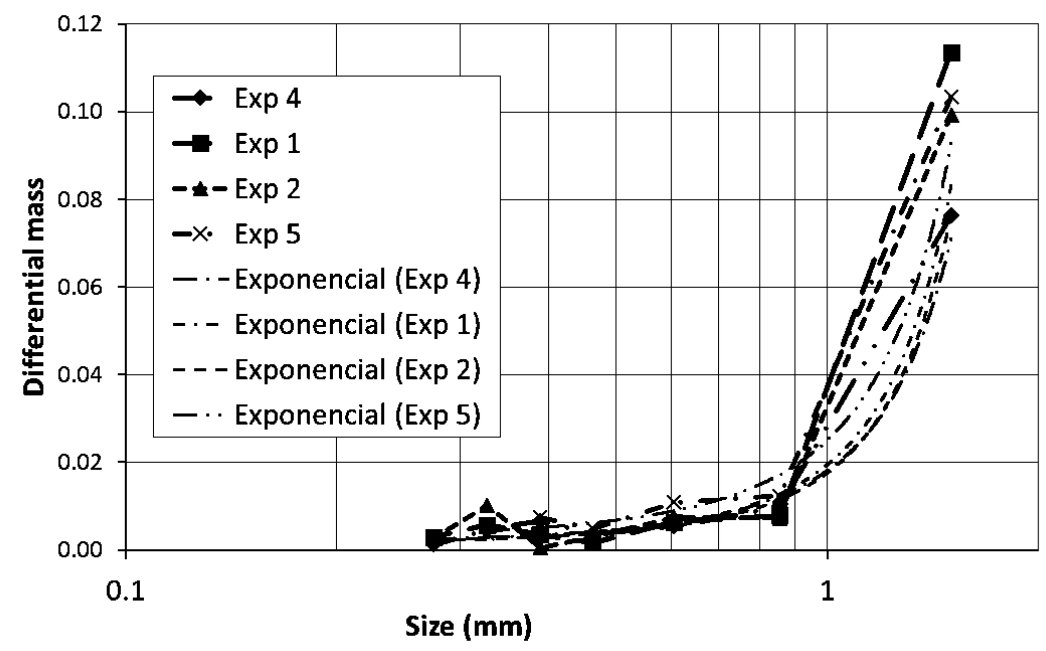

Figure 6. Plot of the difference between the differential mass of a sample from an internal feeding point of the mill and the final product and its consequently exponential regression function for each experiment. 
Table 2. Experimental parameters for the exponential selection function.

\begin{tabular}{lccc}
\hline Experiment & $\omega$ & $\beta$ & $\mathrm{R}$ \\
\hline 1 & 0.0011 & 2.9074 & 0.92 \\
2 & 0.0009 & 2.9447 & 0.80 \\
4 & 0.0012 & 2.7330 & 0.95 \\
5 & 0.0022 & 2.4617 & 0.96 \\
Average & 0.0010 & 2.7617 & \\
Standard deviation & 0.0002 & 0.2203 & \\
\hline
\end{tabular}

The experimental average values achieved for this selection function are $\omega=0.001067$ and $\beta=2.7617$. These values were used in the back-calculation to obtain the parameters of the model. As a goodness-of-fit indicator the correlation coefficient $\mathrm{R}$ was from 0.80 to 0.96 , and it was above 0.90 in three of the four cases. The finest particles fit very well, whereas the coarsest particles varied (Table 2). The standard deviation was 0.0015 for the $\omega$ parameter and 0.22 for the $\beta$ parameter. This selection function derived approximately $15 \%$ of the mass to piston flow process.

The back-calculation results are plotted as simulated curves in Figure 7, and the related parameters are indicated in Table 3. The simulated curves follow the experimental points with an adequate fitting, and the error of these adjustments shows low values, from 0.123 to 0.375 .
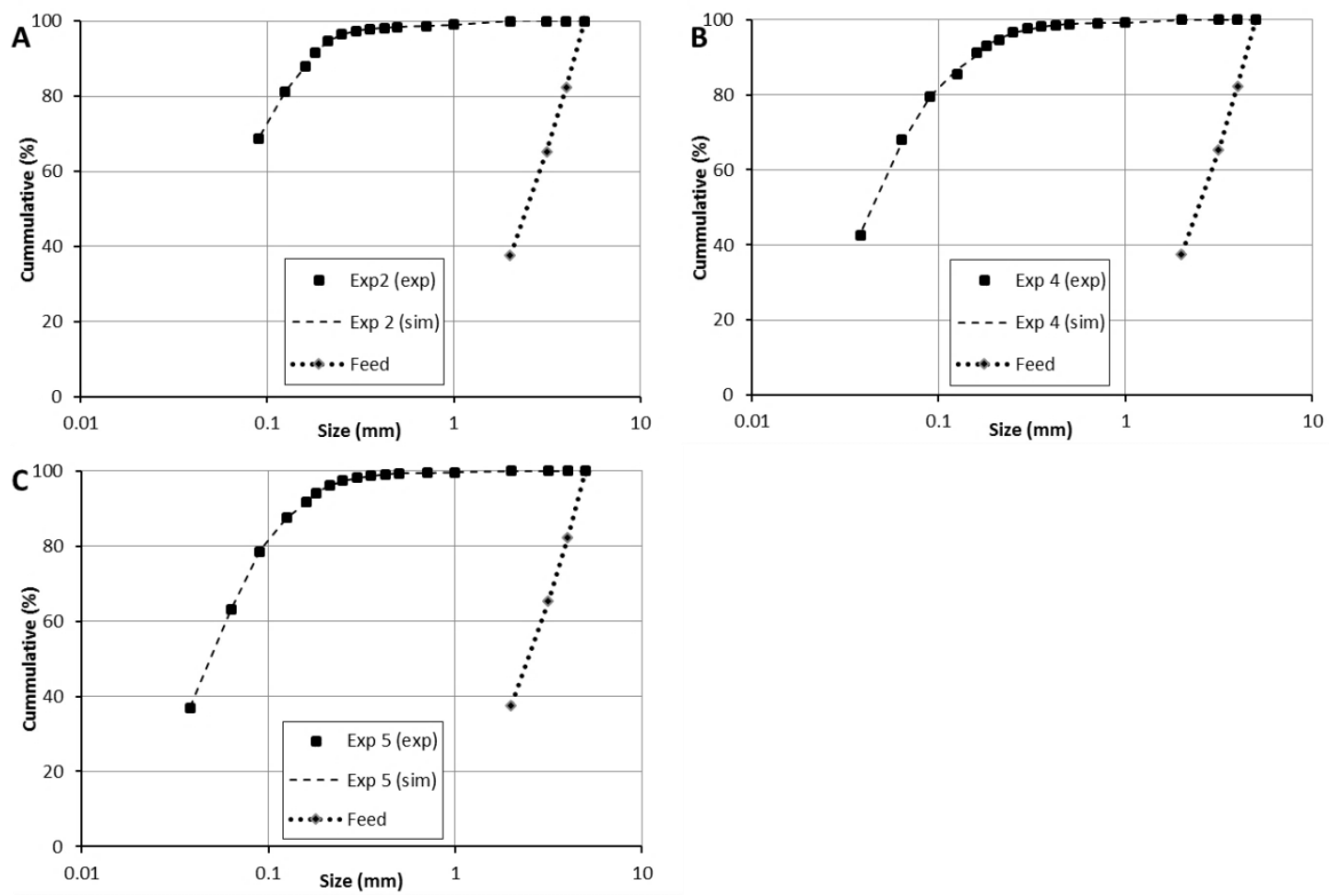

Figure 7. Experimental (exp) and simulated (sim) particle size distributions for the experiments 2 (A), 4 (B) and $5(\mathrm{C})$. 
The back-calculated parameters show similar values for the different experiments. In two cases the standard deviation was 0.000 , and in the other case it was 0.060 , all extremely low values. This can be justified because the experiments have the same operational conditions.

Table 3. Back-calculated parameters of representative experiments.

\begin{tabular}{lrrrrc}
\hline Parameters & Exp 2 & Exp 4 & Exp 5 & Average & Standard deviation \\
\hline $\mathrm{k}$ & 0.100 & 0.100 & 0.100 & 0.100 & 0.000 \\
$\mathrm{n}_{1}$ & 1.000 & 1.000 & 0.896 & 0.965 & 0.060 \\
$\mathrm{n}_{2}$ & 13.928 & 20.000 & 10.001 & 14.643 & 5.038 \\
$\mathrm{~S}_{1}{ }^{\mathrm{E}}$ & 31.429 & 20.000 & 23.811 & 25.080 & 5.819 \\
$\alpha$ & 2.895 & 2.409 & 2.589 & 2.631 & 0.245 \\
$\wedge$ & 7.722 & 6.943 & 6.490 & 7.052 & 0.623 \\
$\mu$ & 1.000 & 1.000 & 1.000 & 1.000 & 0.000 \\
Error & 0.123 & 0.375 & 0.135 & & \\
\hline
\end{tabular}

To demonstrate that the model presented in this work fits better than the perfectly mixed mill, a comparison of the simulations of the piston flow model against the perfectly mixed model has been made (Figure 8). The real product is closer to the product of the new model than to that of the perfectly mixed model.

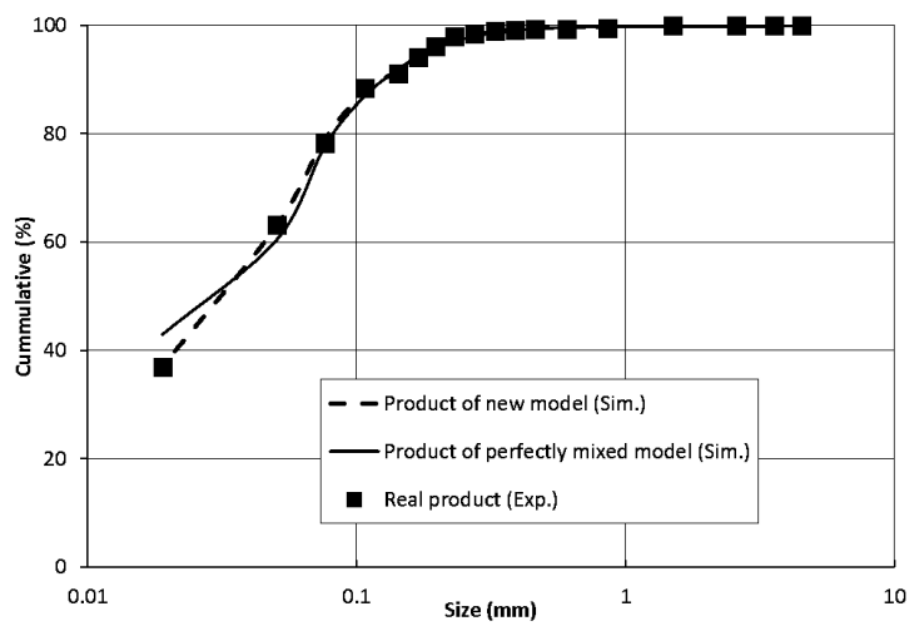

Figure 8. Experimental and predicted curves of the new model and the perfectly mixed mill model for Experiment 5.

Another experiment (Exp. 1) was developed to validate the previously back-calculated parameters. The average parameters shown in Table 2 were used to simulate experiment 1 (Figure 9). 


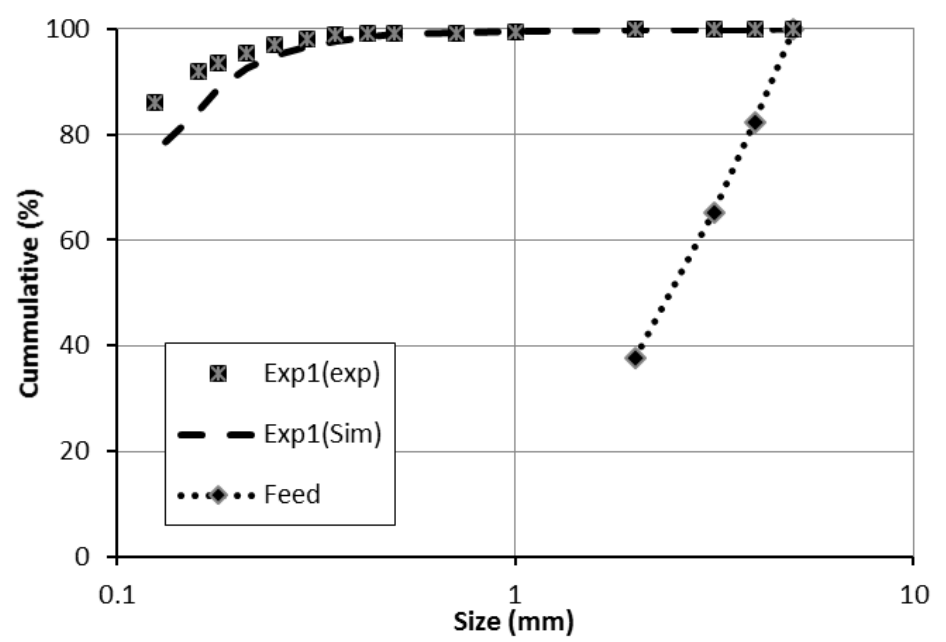

Figure 9. Experimental and predicted curve of the total product mesh size distribution of experiment 1 . The simulated curve used the average parameters of experiments 2,4 and 5.

The fitting error, 0.30, demonstrates the goodness of the adjustment between experimental values and the simulated curve (Figure 9). The best adjustment was in the coarse particle sizes, and most of the error was accumulated in the fine particle sizes. These results indicate that those obtained with the balanced population model for a ball mill in dry conditions is a real alternative for modelling the milling process.

\section{Conclusions}

The comminution in a continuous ball mill can be described as a dual process. However, when a perfectly mixed mill process is predominant, a certain percentage of particles follow the piston flow phenomenon. The observation inside a lab-scale mill, where different samples from the feed inlet, the centre and the exit of the mill were obtained, evidences this behaviour. The analysis of the particle size distribution of the cumulative mass and the differential mas from these samples reinforces this proposal.

A mathematical expression is presented as a selection function, which describes the probability of the particles going to this stage. The exponential regression was based on the plot of the difference between the differential mass of the product and the sample obtained from the feed inlet of the mill. A new population balance model is presented, with two stages, with a perfectly mixed mill solution combined with a piston flow equation as a second stage. The breakage function and the specific rate of breakage function parameters were found using back-calculation techniques. Theses parameters were used for validation, and they show an excellent prediction of the product.

\section{Acknowledgements}

This work is part of the OptimOre project. This project has received funding from the European Union's Horizon 2020 research and innovation programme under grant agreement No 642201. The Wolfram Bergbau and Hütten enterprise helped in the sampling of Mittersill.

\section{References}

Austin, L.G., 1972. A Review-Introduction to the mathematical description of grinding as a rate process, Powder Technology 5, 1-17. 
Austin, L.G., Klimpel, R.R., Luckie, P.T., 1984. Process Engineering of Size Reduction: Ball Milling, SME/AIME, New York. pp. 84-86.

Austin, L.G., Menacho, J.M. and Pearcy, F., 1987. A general model for semi-autogenous and autogenous milling. APCOM 87. Proceedings of the Twentieth International Symposium on the Application of Computers and Mathematics in the Mineral Industries. Volume 2: Metallurgy. Johannesburg, SAIMM, 1987. 107126.

Bilgili, E., Hamey, R., Scarlett, B., 2004. Nano-milling of pigment agglomerates using a wet stirred media mill: elucidation of the kinetics and breakage mechanisms. Proceedings, 2nd International Conference on Population Balance Modelling, Valencia, Spain, Paper No. 20.

Bilgili, E., Yepes, J., Scarlett, B., 2006. Formulation of a non-linear framework for population balance modeling of batch grinding: beyond first-order kinetics. Chem. Eng. Sci. 61, 33-44.

Cleary, P.W., Morrison, R.D., 2011. Understanding fine ore breakage in a laboratory scale ball mill using DEM. Minerals Engineering 24, 352-366.

Datta, A., Rajamani, R.K., 2002. A direct approach of modeling batch grinding in ball mills using population balance principles and impact energy distribution. Int. J. Miner. Process. 64, 181-200.

Epstein, B., 1947. The mathematical description of certain breakage mechanisms leading to the logarithmicnormal distribution. J. Franklin Inst., 244, 471-477.

Grupta, V.K., Sharma, S., 2014. Analysis of ball mill grinding operation using mill power specific kinetic parameters. Advanced powder technology 25, 625-634.

Hennart, S.L.A., Wildeboer, W.J., van Hee, P., Meestersa, G.M.H., 2009. Identification of the grinding mechanisms and their origin in a stirred ball mill using population balances. Chemical Engineering Science 64, 4123-4130.

King, R.P., 2001. Modelling and simulation of mineral processing systems. Butterworth-Heinemann. ISBN 0 750648848.

King, R.P., Bourgeois, F., 1993. Measurement of fracture energy during single-particle fracture. Minerals Engineering 6, 353-367.

King, R.P., Schneider, C., 1993. Mineral Liberation in continuous milling circuits. Proc. XVIII International Mineral Processing Congress, Aus. Inst. Mining Metall.

Morrell, S., Sterns, U.J., Weller, K.R., 1993. The application of population balance models to very fine grinding in tower mills. XIX int. Min. Proc. Congress, Sydney, 61-66.

Reid, K. J., 1965. A solution to the batch grinding equation. Chemical Engineering Science 20, 953-963.

Soni, R.K., Eswaraiah, C., Mishra, B.K., 2015. A novel and direct approach for modeling and simulation of impact grinding. Advanced Powder Technology 26, 1031-1039.

Venkataraman, K.S., Fuerstenau, D.W., 1984. Application of the population balance model to the grinding of mixtures of minerals. . Powder Technology 39, 133-142.

Wang, M.H., Yang, R.Y., Yu, A.B., 2012. DEM investigation of energy distribution and particle breakage in tumbling ball mills. Powder Technology 223, 83-91.

Weerasekara, N.S., Powell, M.S., Cleary, P.W., Tavares, L.M., Evertsson, M., Morrison, R.D., Quist, J., Carvalho, R.M., 2013. The contribution of DEM to the science of comminution. Powder Technology 248, 3-24.

Whiten, W. J., Walter, G. W., White, M. E., 1979. A breakage function suitable for crusher models. 4th Tewkesbury Symposium, Melbourne, pp 19.1-19.3.

Yu, P., Xie, W., Liu, L., Powell, M., 2014. Development of a dynamic mill model structure for tumbling mills. Proceedings, 27th International Mineral Processing Congress, Santiago, Chile.

Zhang, C., Nguyen, G.D., Kodikara, J., 2016. An application of breakage mechanics for predicting energy-size reduction relationships in comminution. Powder Technology 287, 121-130. 